\title{
Gender Differences in Social Relationships, Social Integration and Substance Use
}

\author{
Gloria Jones-Johnson ${ }^{1}$, Matt DeLisi ${ }^{1}$, Andy Hochstetler ${ }^{1}$, \\ W. Roy Johnson ${ }^{2}$, Natalia Frishman ${ }^{1}$ \\ ${ }^{1}$ Department of Sociology, Iowa State University, Ames, USA \\ ${ }^{2}$ Department of Management, Iowa State University, Ames, USA \\ Email: gij@iastate.edu
}

Received September $15^{\text {th }}, 2012$; revised October $25^{\text {th }}, 2012$; accepted November $9^{\text {th }}, 2012$

\begin{abstract}
Although numerous studies have examined the relationship between family and religion on delinquency, there have not been studies of the relationship between parents, friends, and religion on substance use among adults. The analysis for this study was based on two waves of data (Wave 1, 1986 and Wave 2, 1989) of the Americans' Changing Lives Survey. The results revealed that social relationships, social integration and attendance at religious services influence the number of drinks and cigarettes smoked per day among adults. Parental influence varies by gender. The implications for social control, social networks and gender perspectives are discussed.
\end{abstract}

Keywords: Gender and Substance Use; Social Relationships and Substance Use; Gender and Social Relationships

\section{Introduction}

Developmental and life-course perspectives on crime suggest that contextual factors in life and events and choices throughout the life course influence patterns of delinquency (Farrington, 2005; Sampson \& Laub, 1993). Sampson and Laub's (1993, 2005) age-graded life-course theory of crime and other socialcontrol perspectives suggest that family and religion may be especially important influences on patterns of delinquency because they are primary sources of social control, support and integration. In a recent study, Petts (2009) used data from the NLSY79 to examine whether family and religious characteristics influence individual-level delinquency trajectories from early adolescence through young adulthood. The results suggest that residing with two parents deter youths from becoming delinquent and that supportive parenting practices reduce their likelihood of becoming involved in delinquent behavior early in adolescence. Although numerous studies have examined the relationship between family and religion on delinquency, there have not been studies of the relationship between parents, friends and religion on substance use among adults. This study examines the effects of social relationships, social integration and attendance at religious services on the number of drinks and cigarettes smoked per day among adults based on two waves of data of the Americans' Changing Lives Survey.

\section{Gender and Substance Use}

Studies on substance use have implicated gender as an important determinant of behavior and outcomes (Horwitz \& White, 1987; Robbins, 1989). The convergence hypothesis predicts that men and women would adopt similar patterns of drinking as their social roles converge (Bell, Havlicek, \& Roncek, 1984; Calahan, 1970; Ferrance, 1980; Fillmore, 1984; Fraser, 1973, Wechsler, 1980; Wilsnack \& Wilsnack, 1978). Based on the logic of the convergence hypothesis, role-related changes connected to women's labor force participation would not only challenge traditional family roles, but would also transform the attitudes of both men and women in other domains, including the appropriateness of certain types of social behavior, such as alcohol consumption (Parker et al., 1980; Temple, 1987; Wilsnack, Wilsnack, \& Klassen, 1984). Contrary to the convergence hypothesis, adolescent and adult males still drink more frequently and consume larger quantities of alcohol than their female counterparts (Johnson et al., 2001; Lo, 2000; Peralta and Cruz, 2006; Wallace \& Bachman, 1991). In this study we examine gender differences in alcohol consumption and cigarette smoking among adults.

\section{Peer Relationships}

Peer relationships are considered the primary factor involved in whether youth decide to engage in and maintain substance use (Ennett \& Bauman, 1993; Ennett \& Bauman, 2000; Kobus, 2003; Valente, 2003) and peers reinforce substance use behaviors (Epstein et al., 1999). Several studies have found that substance-using youth more likely to have substance-using friends (Alexander et al., 2001; Bauman et al., 1984; Ennett \& Bauman, 1993, 1994; Ennett, Bauman, \& Koch, 1994; Rai et al., 2003; Sieving et al., 2000; Sussman et al., 1990; Unger et al., 2001; Windle, 2000). A body of literature stresses the social capital that is available in open networks produce advantages for teenagers and young adults (Kim \& Schneider, 2005; Morgan and Sorensen, 1999; Offer and Schneider, 2007; Sullivan, 1991; Bearman \& Moody, 2004). Bott (1971) explored the effects of open and diffused networks and pointed out that with the freedom afforded by open networks, other important relations (e.g. strong ties and significant others) can have their influence enhanced. We apply this logic to suggest that satisfying relationship with friends could reduce substance use. Sampson 
and colleagues (2006) found that adult relationships affect patterns of delinquency net of selection factors.

\section{Religious Involvement}

According to Smith (2003), religious institutions provide resources, such as support networks and teaching to help individuals cope with and find meaning in stressful events. These resources may be especially beneficial to adults who are at high risk for substance use. Rohrbaugh and Jessor (1975) identify several processes of internalized social control through which personal religiosity may influence behavior. They maintain that religion sensitizes individuals to moral issues and acceptable standards of behavior, and it offers a deity as a source of punishment and wrath. Thus, active religious involvement should foster an interest in abiding by religious precepts. High religious participation should be related to reduce substance use because the fear of divine punishment would make a person less likely to disobey the rules of the faith. Most studies on the association of religion with substance use have found an inverse, contemporaneous relationship (e.g., Bowie, Ensminger, \& Robertson, 2005; Gorsuch, 1995).

\section{Social Integration}

Baum and Ziersch (2003) point out that the multidisciplinary literature on individual and public health labeled "social capital" research equates social capital with other relationship-based concepts such as social networks, social support, social integration, and social cohesion. Brissette, Cohen and Seeman (2000) noted that social integration is the extent of participation in social networks, indicated by active engagement in social roles and social activities, and cognitive identification with network members" (p. 151) According to Bellah et al. (1996), social integration theory posits that involvement in formal and informal organizations supply social support and peers which foster a positive sense of the self. Hirschi (1969) maintains that attachment to organizations works as a social control. We examine the impact of social integration on substance use.

\section{Hypotheses}

We propose sets of hypotheses based on theoretical interests. The first set of hypotheses states that social relationships have a negative impact on substance use. Specifically, a positive relationship with mother, father and friends decreases the number of cigarettes and drinks per day. Second set of hypotheses state that formal and informal social integration decrease substance use. The stronger the formal and informal social integration, the less smoking and drinking. The third hypothesis asserts that frequency of attendance at religious services decreases substance use. As religious attendance increases, substance use decreases. Fourth, we hypothesize that the positive effects of social relationships, social integration and religion on substance use would be stronger for women than men. Fifth, we expect social relationships to interact with religious attendance to reduce substance use. For example, those people who have a positive relationship with their mother and frequently attend religious services would drinks less and smoke fewer cigarettes. Sixth, formal social integration may provide greater social control and attachment; therefore, it is expected to have a stronger impact on substance use than informal social integration.

We control for race, education, and income. According to
Bachman et al. (2002), individuals who juggle the duties and responsibilities related to work, marriage, and parenthood simply have less time available to engage in drinking behavior. Many studies have found a strong protective effect of marriage on substance use and abuse (for a review, see Rhule-Louie \& McMahon, 2007). Cross-sectional studies have found economic resources to be inversely related to drug use in adulthood (e.g., National Institute on Drug Abuse). Research studies over the past several decades have found cigarettes use to be concentrated among lower education, occupational prestige, and income groups (Barbeau, Krieger, \& Soobader, 2004; Honjo et al., 2006).

\section{Methods}

\section{Participants}

The data come from the Americans' Changing Lives Survey, a stratified, multistage area probability sample of non-institutionalized adults age 25 and older living in the coterminous United States with over-sampling of both adults age 60 and older and African Americans. The wave 1 was conducted in 1986 and consisted of face-to-face interviews with 3617 respondents (representing $70 \%$ of sampled households and $68 \%$ of sampled individuals). Wave 2 conducted in 1989, also involved face-toface interviews with 2867 (83\%) of wave 1 survivors. In 1994, approximately 7.5 years after baseline, wave 3 was conducted via telephone or face-to-face interviews with 2562 participants or their proxies (representing $83 \%$ of wave 1 survivors). Additional information on the study design is published elsewhere (House et al., 1994; House et al., 1990). The analysis for this study was based on data from $\mathrm{T}_{1}$ (1986) and $\mathrm{T}_{2}$ (1989).

\section{Variables}

\section{Dependent Variables}

We use two dependent variables for this study: 1) number of drinks per day; and 2) number of cigarettes per day. The survey item asked respondents to report how many drinks that had per day and how many cigarettes they smoked per day. Each measure is coded as a simple count.

\section{Independent Variables}

Independent variables of theoretical interest include relationship with mother, father and friends. Mother relationship is an index of the quality of interaction with one's mother. The respondent was asked to report on four questions which asked the extent to which there are too many demands from mother, critical of mother, love and care for mother (reverse scored) and will listen to mother (reverse scored). The responses ranged from (1) almost always to (4) never. These same four questions were asked for father and friend and were used to create a scale for father relationship and friend relationship. The reliability for mother relationship $\mathrm{T}_{1}$ (Cronbach's alpha $\left.=.64\right)$ and $\mathrm{T}_{2}$ (Cronbach's alpha $=.63)$. For father relationship, the reliability at $T_{1}$ $($ Cronbach's alpha $=.58)$ and $\mathrm{T}_{2}($ Cronbach's alpha $=.56)$. The reliability for friend relationship at $\mathrm{T}_{1}($ Cronbach's alpha $=.59)$ and $\mathrm{T}_{2}($ Cronbach's alpha $=.59)$.

\section{Social Integration}

Informal social integration is an index that combines two 
questions. The respondent was asked "In a typical week, about how many times do you talk on the telephone with friends, neighbors or relatives". The second question asked "How often do you get together with friends, neighbors or relatives and do things like go out together or visit in each other's homes?" The responses ranged from (1) more than once a day to (6) never and they were reverse scored. The Cronbach's alpha $=.85$ at $\mathrm{T}_{1}$ and .89 at $\mathrm{T}_{2}$.

Formal social integration also is a two-item index. It consists of the following two questions: "How often do you attend meetings or programs of groups, clubs or organizations that you belong to?" and "How often do you participate in leisure or social activities by yourself or with people other than your spouse/partner?" For both questions the responses were reverse scored and ranged from (6) more than once a week to (1) never. At $\mathrm{T}_{1}$ the Cronbach's alpha is .84 and at $\mathrm{T}_{2} .86$.

\section{Religious Involvement}

Frequency of attendance at religious services is a one item measure which asks the respondent "How often do you usually attend religious services?" The responses ranged from (1) more than once a week to (6) never and was reverse scored such that a 6 represents a high frequency of attendance.

\section{Control Variables}

Control variables include age, gender, employment status, income, marital status and race. Age is coded in years and education is measured as total years of completed education. Gen$\operatorname{der}($ female $=1,0=$ male $)$ and employment status (employed $=$ $1,0=$ not employed). Income was measured as the combined income in the preceding year from all sources for respondents and their spouses in dollars. Marital status is coded (married = $1,0=$ not married). Race is five dummy variables that distinguish Whites $(\mathrm{N}=2339)$, African Americans $(\mathrm{N}=1174) \mathrm{Na}-$ tive Americans $(\mathrm{N}=138)$, Asians $(\mathrm{N}=33)$ and Hispanics $(\mathrm{N}=$ 165).

The analysis was conducted in three stages. First, models were estimated that included demographic control variables, social relationships, social integration, religious involvement for $\mathrm{T}_{1}$ and $\mathrm{T}_{2}$ that predict drinking and cigarette use. Second, we estimated models of social relationships, social integration, religious involvement drinking and cigarette use separately for males and females for $T_{1}$ and $T_{2}$. Finally, we estimated model of the full sample that included a multiplicative term involving social relationships (mother, father and friend relationship each separately) and attendance at religious services on number of drinks and cigarettes smoked per day.

\section{Results}

Table 1 presents the regression results at $T_{1}$ for number of cigarettes and number of drinks at $T_{1}$ with control variables included. Equation 1 shows that sex is a marginally significant predictor of number of cigarettes smoked per day and suggests

Table 1.

Regression coefficients predicting number of cigarettes and drinks per day with control variables $T_{1}$.

\begin{tabular}{|c|c|c|c|c|c|c|}
\hline \multirow{3}{*}{ Independent variable } & \multicolumn{3}{|c|}{ Cigarettes $T_{1}$} & \multicolumn{3}{|c|}{ Drinks $T_{1}$} \\
\hline & \multicolumn{3}{|c|}{ Equation 1} & \multicolumn{3}{|c|}{ Equation 2} \\
\hline & Coeff & Std error & Beta & Coeff & Std Error & Beta \\
\hline Constant & $28.71^{* *}$ & 8.24 & --- & $6.54^{* *}$ & 1.11 & $-\overline{---}$ \\
\hline Mother relationship $T_{1}$ & -.26 & .22 & -.07 & -.05 .09 & .03 & -.07 \\
\hline Father relationship $T_{1}$ & .29 & .21 & .08 & .01 & .03 & .01 \\
\hline Friends relationship $T_{1}$ & -.26 & .23 & -.07 & .01 & .04 & .01 \\
\hline Attend religious services $T_{1}$ & -.62 & .62 & -.09 & -.06 & .09 & -.04 \\
\hline Education & -.27 & .27 & -.06 & $-.12^{* *}$ & .04 & -.13 \\
\hline Age & -.06 & .07 & -.05 & $-.03^{* *}$ & .01 & -.10 \\
\hline Sex (male) & 2.16 .07 & 1.23 & .09 & $.96^{* *}$ & .18 & .22 \\
\hline Married & -.35 & 1.37 & -.02 & -.32 .09 & .19 & -.07 \\
\hline White & 1.67 & 4.43 & .07 & -.62 & .51 & -.13 \\
\hline Black & -3.91 & 4.50 & -.16 & -.75 & .51 & -.15 \\
\hline American Indian & 3.35 & 3.13 & .06 & .26 & .49 & .02 \\
\hline Asian & 1.78 & 9.02 & .01 & -1.05 & .90 & -.05 \\
\hline Hispanic & -8.27 & 5.83 & -.11 & .16 & .75 & .01 \\
\hline Working $\mathrm{T}_{1}$ & -1.78 & 1.39 & -.07 & -.30 & .23 & -.05 \\
\hline Family income & .05 & .04 & .08 & .01 & .02 & -.01 \\
\hline Informal social integration & -.30 & .61 & -.03 & -.08 & .10 & -.03 \\
\hline \multirow[t]{3}{*}{ Formal social integration } & -.01 & 1.13 & .01 & -.03 & .16 & -.01 \\
\hline & \multicolumn{3}{|c|}{$\mathrm{F}=2.65^{* *}$} & \multicolumn{3}{|c|}{$\mathrm{F}=4.31^{* *}$} \\
\hline & \multicolumn{3}{|c|}{$\mathrm{R}^{2}=.11$} & \multicolumn{3}{|c|}{$\mathrm{R}^{2}=.10$} \\
\hline
\end{tabular}

Note: ${ }^{* *}$ significant at $p<.01$. 
that men have a tendency to smoke more than women. Equation 2 indicate that education, age, and gender are significant predictors of number of drinks per day; the highly educate and those older are significantly less likely to drink heavily while men are significantly more likely to drink heavily compared to women. The marginally significant coefficient for married suggests that those who are married have a tendency to drink less than the non-married. It is noteworthy that relationship with mother is a marginally significant predictor of number of drinks per day even with all of the control variables included in the model. Thus, there is a tendency for those people who have a positive relationship with their mother to drink less. However, only ten percent of the variance is explained in number of cigarettes and drinks per day with the control variables included.

The regression results for $T_{2}$ control variables on number of cigarettes and number of drinks per day are shown in Table 2. Education and age are the significant predictors of number of cigarettes smoked per day and suggest that the highly educated are significantly less likely to smoke heavily whereas as people get older they are more likely to smoke heavily. Equation (2) reveals that education, age, gender, married are significant predictors of number of drinks per day and indicate that the educated, people who are older and those married are significantly less likely to smoke heavily. The significant coefficient for gender shows that men drink more than women. With the control variables included, relationship with father is a significant predictor and relationship with mother is a marginally signifi- cant predictor of number of drinks per day. Thus, those people who have a positive relationship with their fathers are significantly more likely to drink heavily while those who have a positive relationship with their mother have a tendency to drink less drinks per day. The results for the control variables are consistent with prior studies (Johnson et al., 2001; Lo, 2000; Peralta \& Cruz, 2006; Wallace \& Bachman, 1991).

Based on our hypothesis and the significant coefficient for gender, we ran the models separately for men and women at $T_{1}$ and $\mathrm{T}_{2}$. The regression results for women are presented in Table 3. At $T_{1}$, frequency attend religious services is the only significant predictor of number of cigarettes smoked per day and suggests that those women who frequently attend religious services are significantly less likely to smoke heavily. Relationship with mother is the only significant predictor of number of drinks per day and indicates that those women who have positive relationships with their mothers are significantly less likely to drink heavily. These results support our hypothesis. At $T_{2}$, number of cigarettes smoked per day at $T_{1}$ and relationship with mother is the significant predictors of number of cigarettes smoked per day. Those women who smoked heavily at $\mathrm{T}_{1}$ are significantly more likely to smoke heavily at $\mathrm{T}_{2}$, while those women who have a positive relationship with their mothers at $\mathrm{T}_{2}$ are significantly more likely to smoke heavily at $\mathrm{T}_{2}$. These results contradict our hypothesis. However, number of drinks per day at $T_{1}$ is the only significant predictor of number of drinks per day at $T_{2}$ indicating that those women who drank

Table 2.

Regression coefficients predicting number of cigarettes and drinks per day with control variables $T_{2}$.

\begin{tabular}{|c|c|c|c|c|c|c|}
\hline \multirow{3}{*}{ Independent Variable } & \multicolumn{3}{|c|}{ Cigarettes $T_{2}$} & \multicolumn{3}{|c|}{ Drinks $T_{2}$} \\
\hline & \multicolumn{3}{|c|}{ Equation (1) } & \multicolumn{3}{|c|}{ Equation (2) } \\
\hline & Coeff & Std error & Beta & Coeff & Std Error & Beta \\
\hline Constant & 21.25 .07 & 11.65 & --- & $8.02^{* *}$ & 1.25 & --- \\
\hline Mother relationship $\mathrm{T}_{2}$ & -.09 & .32 & -.02 & -.07 .06 & .04 & -.09 \\
\hline Father relationship $T_{2}$ & .21 & .28 & .05 & $.09^{* *}$ & .03 & .12 \\
\hline Friends relationship $T_{2}$ & -.28 & .30 & -.07 & -.06 & .04 & -.07 \\
\hline Attend religious services $T_{2}$ & -.84 & .84 & -.12 & .01 & .01 & .01 \\
\hline Education & $-1.06^{* *}$ & .37 & -.20 & $-.23^{* *}$ & .04 & -.26 \\
\hline Age & $.25^{* *}$ & .10 & .18 & $-.03^{* *}$ & .01 & -.11 \\
\hline Sex (male) & 2.22 & 1.54 & .10 & $1.07^{* *}$ & .19 & .27 \\
\hline Married & 1.33 & 1.79 & .06 & $-.68^{* *}$ & .22 & -.17 \\
\hline White & 7.26 & 5.81 & .31 & -.74 & .53 & -.16 \\
\hline Black & 2.71 & 5.71 & .11 & -.81 & .53 & -.17 \\
\hline American Indian & 1.65 & 3.60 & .03 & .65 & .58 & .05 \\
\hline Asian & -5.21 & 7.93 & -.06 & -.96 & .75 & -.06 \\
\hline Hispanic & 2.93 & 12.48 & .02 & .17 & .88 & .01 \\
\hline Working $\mathrm{T}_{2}$ & -1.07 & 1.91 & -.04 & -.39 & .25 & -.07 \\
\hline Family income & -.01 & .04 & -.01 & .01 & .01 & .03 \\
\hline Informal social integration & .43 & .85 & .04 & -.04 & .11 & -.02 \\
\hline \multirow[t]{3}{*}{ Formal social integration } & -.11 & 1.62 & -.01 & -.19 & .18 & -.09 \\
\hline & \multicolumn{3}{|c|}{$\mathrm{F}=2.45^{* *}$} & \multicolumn{3}{|c|}{$\mathrm{F}=7.23^{* *}$} \\
\hline & \multicolumn{3}{|c|}{$\mathrm{R}^{2}=.17$} & \multicolumn{3}{|c|}{$\mathrm{R}^{2}=.23$} \\
\hline
\end{tabular}

Note: ${ }^{* *}$ significant at $p<.01$. 
Table 3.

Regression coefficients predicting number of cigarettes and drinks per day for women $T_{1}$ and $T_{2}$.

\begin{tabular}{|c|c|c|c|c|c|c|}
\hline \multirow{3}{*}{$\frac{\mathrm{T}_{1}}{\text { Independent variable }}$} & \multicolumn{3}{|c|}{ Equation 1} & \multicolumn{3}{|c|}{ Equation 2} \\
\hline & \multicolumn{3}{|c|}{ Cigarettes } & \multicolumn{3}{|c|}{ Drinks } \\
\hline & Coeff & Std Error & Beta & Coeff & Std error & Beta \\
\hline Constant & $24.50^{* *}$ & 6.25 & --- & $2.29^{* *}$ & .91 & --- \\
\hline Mother relationship & -.19 & .28 & -.05 & $-.08^{*}$ & .04 & -.13 \\
\hline Father relationship & .20 & .27 & .06 & .02 & .04 & .04 \\
\hline Friends relationship & -.12 & .31 & -.03 & .05 & .04 & .07 \\
\hline Attend religious services & $-1.92^{* *}$ & .79 & -.28 & .03 & .11 & .03 \\
\hline Informal social integration & .68 & .76 & .06 & -.09 & .12 & -.04 \\
\hline \multirow[t]{3}{*}{ Formal social integration } & .53 & 1.44 & .04 & -.20 & .20 & -.09 \\
\hline & \multicolumn{3}{|c|}{$\mathrm{F}=2.67^{* *}$} & \multicolumn{3}{|c|}{$\mathrm{F}=1.34$} \\
\hline & \multicolumn{3}{|c|}{$\mathrm{R}^{2}=.07$} & \multicolumn{3}{|c|}{$\mathrm{R}^{2}=.03$} \\
\hline $\mathrm{T}_{2}$ & \multicolumn{3}{|c|}{ Cigarettes } & \multicolumn{3}{|c|}{ Drinks } \\
\hline Constant & $-6.70_{\mathrm{NS}}$ & 7.40 & --- & $1.33_{\mathrm{NS}}$ & 1.05 & --- \\
\hline Drinks per day $T_{1}$ & --- & --- & --- & $.48^{* *}$ & .08 & .39 \\
\hline Cigarettes per day $T_{1}$ & $.61^{* *}$ & .08 & .62 & --- & --- & --- \\
\hline Mother relationship & $.68^{*}$ & .33 & .19 & -.04 & .04 & -.07 \\
\hline Father relationship & -.07 & .28 & -.02 & .01 & .04 & .02 \\
\hline Friends relationship & .12 & .32 & .03 & -.01 & .05 & -.01 \\
\hline Attend religious services & .29 & .76 & .05 & .08 & .11 & .08 \\
\hline Informal social integration & -.92 & .84 & -.09 & -.10 & .14 & -.05 \\
\hline \multirow[t]{3}{*}{ Formal social integration } & -.99 & 1.59 & -.08 & -.33 & .22 & -.18 \\
\hline & \multicolumn{3}{|c|}{$\mathrm{F}=9.52^{* *}$} & \multicolumn{3}{|c|}{$\mathrm{F}=6.56^{* *}$} \\
\hline & \multicolumn{3}{|c|}{$\mathrm{R}^{2}=.41$} & \multicolumn{3}{|c|}{$\mathrm{R}^{2}=.20$} \\
\hline
\end{tabular}

Note: ${ }^{* *}$ significant at $p<.01 ;{ }^{*}$ significant at $p<.05$.

heavily at $T_{1}$ are significantly more likely to drink heavily at $T_{2}$. At $T_{2}$, the variables explain twice as much variance in number of cigarettes smoked compared to number of drinks per day (41 and 20 per cent respectively).

Table 4 shows the regression results for men of number of cigarettes and drinks per day at $\mathrm{T}_{1}$ and $\mathrm{T}_{2}$. At $\mathrm{T}_{1}$ there are no significant predictors of number of cigarettes smoked or number of drinks per day for men. However at $T_{2}$, number of cigarettes smoked per day at $T_{1}$ is a significant predictor and suggests that those men who smoked heavily at $T_{1}$ are significantly more likely to smoke heavily at $T_{2}$. Relationship with mother is a marginally significant predictor and indicates that those men who have a positive relationship with their mothers have a tendency to smoke less. As expected number of drinks at $T_{1}$ is a significant predictor which suggests that those men who drink heavily at $T_{1}$ are significantly more likely to drink heavily at $T_{2}$. Relationship with mother and relationship with father are significant predictors of number of drinks at $\mathrm{T}_{2}$. Most interesting, however, is that those men who have a positive relationship with their mothers are significantly less likely to drink heavily, but those men who have a positive relationship with their fathers are significantly more likely to drink heavily. These variables explain almost twenty per cent more variance in number of cigarettes smoked per day compared to the number of drinks per day $\left(\mathrm{R}^{2}=.57\right.$ and .39 , respectively). These results provide mixed support for our hypothesis that women would benefit more from social relationship, social integration and frequency of attendance at religious services than men in terms of reducing substance use. There is an unexpected change in the relationships from $T_{1}$ to $T_{2}$ and an unexpected within gender social relationship effect by substance use. Relationship with mother reduces drinking at $T_{1}$ but increases smoking at $T_{2}$ for women. However, relationship with father has no effect on smoking or drinking for women at $T_{1}$ or $T_{2}$. In contrast, relationship with mother has no effect at $T_{1}$ but reduces smoking and drinking at $\mathrm{T}_{2}$ for men. It is interesting that, relationship with father has no effect on number of cigarettes smoked but increases drinking at $\mathrm{T}_{2}$ for men.

We tested the interaction between social relationship and frequency attended religious services at $T_{1}$ and $T_{2}$ for number of cigarettes smoked per day and number of drinks per day. At $\mathrm{T}_{1}$ only the interaction between relationship with friend and frequency attend religious services was significant. The significant interaction between relationship with friends and frequency attend religious services indicates that those people who have positive relationships with friends and frequently attend religious services are significantly less likely to drink heavily. The interaction between relationship with friends and frequency attend religious services support our hypothesis that family and religion interact to reduce substance use. The interaction between relationship with mother and frequency attend religious services on number of drinks per day is the only significant 
Table 4.

Regression coefficients predicting number of cigarettes and drinks per day for men $T_{1}$ and $T_{2}$.

\begin{tabular}{|c|c|c|c|c|c|c|}
\hline \multirow{3}{*}{$\frac{\mathrm{T}_{1}}{\text { Independent variable }}$} & \multicolumn{3}{|c|}{ Equation 1} & \multicolumn{3}{|c|}{ Equation 2} \\
\hline & \multicolumn{3}{|c|}{ Cigarettes } & \multicolumn{3}{|c|}{ Drinks } \\
\hline & Coeff & Std error & Beta & Coeff & Std error & Beta \\
\hline Constant & $21.85^{* *}$ & 7.48 & --- & $5.21^{* *}$ & 1.17 & --- \\
\hline Mother relationship & -.54 & .36 & -.14 & -.05 & .05 & -.06 \\
\hline Father relationship & .35 & .36 & .08 & -.01 & .05 & -.01 \\
\hline Friends relationship & -.07 & .35 & -.02 & -.06 & .06 & -.07 \\
\hline Attend religious services & .58 & .98 & .08 & -.04 & .14 & -.03 \\
\hline Informal social integration & -.37 & .96 & -.03 & -.03 & .15 & -.01 \\
\hline \multirow[t]{3}{*}{ Formal social integration } & -1.29 & 1.71 & -.11 & -.27 & .25 & -.10 \\
\hline & \multicolumn{3}{|c|}{$\mathrm{F}=.75_{\mathrm{NS}}$} & \multicolumn{3}{|c|}{$\mathrm{F}=1.67_{\mathrm{NS}}$} \\
\hline & \multicolumn{3}{|c|}{$\mathrm{R}^{2}=.03$} & \multicolumn{3}{|c|}{$\mathrm{R}^{2}=.03$} \\
\hline $\mathrm{T}_{2}$ & \multicolumn{3}{|c|}{ Cigarettes } & \multicolumn{3}{|c|}{ Drinks } \\
\hline Constant & $14.47_{\mathrm{NS}}$ & 8.83 & --- & $4.04^{* *}$ & 1.28 & --- \\
\hline Drinks per day $T_{1}$ & --- & --- & --- & $.60^{* *}$ & .06 & .56 \\
\hline Cigarettes per day $T_{1}$ & $.81^{* *}$ & .09 & .71 & --- & -- & --- \\
\hline Mother relationship & $-.73(.07)$ & .40 & -.15 & $-.29^{* *}$ & .06 & -.30 \\
\hline Father relationship & .18 & .34 & .04 & $.15^{* *}$ & .05 & .17 \\
\hline Friends relationship & .06 & .35 & .01 & -.03 & .06 & -.03 \\
\hline Attend religious services & -.65 & 1.07 & -.08 & -.04 & .15 & -.03 \\
\hline Informal Social Integration & .79 & 1.16 & .05 & -.01 & .16 & -.01 \\
\hline \multirow[t]{4}{*}{ Formal Social Integration } & .01 & 1.95 & .01 & .01 & .27 & .01 \\
\hline & \multicolumn{3}{|c|}{$\mathrm{F}=15.99_{\mathrm{NS}}$} & \multicolumn{3}{|c|}{$\mathrm{F}=17.76^{* *}$} \\
\hline & \multicolumn{3}{|c|}{$\mathrm{R}^{2}=.57$} & \multicolumn{3}{|c|}{$\mathrm{R}^{2}=.39$} \\
\hline & \multicolumn{3}{|c|}{$\mathrm{R}^{2}=.03$} & \multicolumn{3}{|c|}{$\mathrm{R}^{2}=.04$} \\
\hline
\end{tabular}

Note: ${ }^{* *}$ significant at $p<.01$.

interaction at $T_{2}$. This interaction indicates that those people who have positive relationships with their mothers and frequently attend religious services are significantly less likely to drink heavily. This interaction supports our hypothesis that family and religion interact to reduce substance use. However, with the interaction term included, there is very little variance explained in number of cigarettes and number of drinks per day (data not shown, available upon request from author).

\section{Discussion}

The results of this study revealed that social relationships, social integration and attendance at religious services influence the number of drinks and cigarettes smoked per day for two waves of a nationally representative survey for older Americans. A person's relationship with their mother and father has different impacts on smoking and drinking behavior. These findings support Sampson and colleagues (2006) finding that adult relationships affect patterns of delinquency net of selection factors. The lack of a significant effect for relationship with friends suggests that peer relationships may not have an influence on adult substance use. The findings support general social control perspective (Durkheim, 1897, 1951; Hirschi, 1969) that family and religion are primary sources of social control, support and integration.

The positive effect of formal social integration on substance use supports Hirschi's (1969) contention that attachment to organizations works as a social control. The significant effects for frequency attend religious services on smoking and drinking are consistent with Neil and Kahn's (1999) observation that engagement with religious communities might also benefit older adults in particular by providing opportunities for socialization and social support in later life. Similarly, Levin and Taylor (1997) suggest that older adults may have been socialized to value religiosity and spirituality more than younger people.

Our study highlights the importance of family and interpersonal relationships as forms of social supports that impacts substance use. Moreover, we found that relationship with mother has the most consistent and persistent effect on substance use, and that the positive effect vary by substance use (drinking vs. cigarettes) and by gender. The relationship with mother for women was positive for drinking and negative for smoking, but it was positive for men whether drinking or smoking. The relationship with father was not a significant factor for women and a negative factor for men for drinking. These findings may 
reflect gender differences in methods of coping with stressful interpersonal family relationships and gender differences in social support in substance use. The quality of relationships adults have with their parents may contribute to substance use and abuse and impact treatment, social support and the stigma associated with substance use. Future research needs to include relationships with parents as a source of social integration by gender, race, and age when examining substance use and abuse.

\section{Conclusion}

This study's finding that relationship with mother increased cigarette smoking for women and relationship with father increased drinking for men are suggestive of the research studies that found that bonds to parents can increase substance use among children (Fleming et al., 1997; Foshee \& Bauman, 1992). Sampson and Laub's (1993) age-graded life course theory of crime and social control perspectives can be used to understand the impact of parents, friends and religion on substance use among adults. In addition, the results of our study support the convergence hypothesis and suggest that the environmental influences on gender roles are prevalent among adult. The findings highlight that gender ideology, which defines expectations regarding the "appropriate" performance of male and female roles (Greenstein, 1995, 1996) and the belief that people change their gender roles and ideologies both between and within generations (Wentworth \& Chell, 2005) are important to understand the role that gender plays in understanding substance use and abuse especially among adults.

The major limitations of the present study are lack of adequate measures of social network related to smoking and drinking and lack of social network level measures such as centrality and density of networks. Measures that directly link social relationships to smoking and drinking would clarify the nature of the effects, especially over time. Future research should also examine late-onset drinking and smoking on social relationships and social integration among adults. A multiple item measure of religious participation or religiosity would enhance our understanding of the role that religion plays in reducing substance use or abuse.

\section{Acknowledgements}

We appreciate the comments of Adam Foley, a graduate student at Iowa State University.

\section{REFERENCES}

Alexander, C., Piazza, M., Mesko, D., \& Valente, T. (2001). PeerNetworks and adolescent cigarette smoking: An analysis of the national longitudinal study of adolescent health. Journal of School Health, 29, 22-30.

Barbeau, E., Krieger, N., \& Soobader, M. (2004). Working class matters: Socioeconomic disadvantage, race/ethnicity, gender and smoking in NHIS 2000. American Journal of Public Health, 94, 269-278. doi:10.2105/AJPH.94.2.269

Baum, F., \& Ziersch, A. (2003). Social capital. Journal of Epidemiology And Community Health, 57, 320-323. doi:10.1136/jech.57.5.320

Bauman, K., Fisher, L., Bryan, E., \& Chenoweth, R. (1984). Antecedents, subjective expected utility and behaviors: A study of adolescent cigarette smoking. Addictive Behavior, 48, 121-136. doi:10.1016/0306-4603(84)90050-9

Bachman, J., O’Malley, P., Schulenberg, J., Johnston, L., Bryant, A., \& Merline, A. (2002). The decline of substance use in young adulthood:
Changes in social activities, roles and beliefs. Mahwah, NJ: Lawrence Erlbaum Associates.

Bearman, P., \& James, M. (2004). Chains of affection: The structure of adolescent romantic and sexual networks. American Journal of Sociology, 110, 44-91. doi:10.1086/386272

Bell, R., Havlicek, P., \& Roncek, D. (1984). Sex differences in the use of alcohol tranquilizers: Testing a role convergence hypothesis. American Journal of Drug and Alcohol Abuse, 10, 551-561. doi: $10.3109 / 00952998409001492$

Bellah, R., Madsen, R., Sullivan, W., Swidler, A., \& Tipton, S. (1996). Habits of the heart: Individualism and commitment in American life. Berkeley, CA: University of California Press.

Bott, E. (1971). Family and social network: Roles, norms, and external relationships (2nd ed.). New York: Free Press.

Bowie, J., Ensminger, M., \& Robertson, S. (2005). The relationship between religious coping style and anxiety over breast cancer among women. Journal of Religious Health, 40, 411-422. doi:10.1023/A:1012873017657

Brissette, I., Cohen, S., \& Seeman, T. (2000). Social integration and social networks. In S. Cohen, L. Underwood, \& B. Gottlieb (Eds.), Social support measurement and intervention (pp. 53-85). New York: Oxford University Press.

Calahan, D. (1970). Problem drinkers. San Francisco, CA: Jossey-Bass. Durkheim, E. (1897). Suicide. New York: Free Press.

Ennett, S., \& Bauman, K. (1993). Peer group structure and adolescent cigarette smoking: A social network analysis. Journal of Health and Social Behavior, 34, 221-236.

Ennett, S., \& Bauman, K. (1994). The contribution of influence and selection to adolescent peer group homogeneity: The case of adolescent cigarette smoking. Journal of Personality and social Behavior, 67, 653-663.

Ennett, S., \& Bauman, K. (2000). Adolescent social networks: Friendship cliques, social isolates, and drug use risk. In W. B. Hansen, S. M. Giles, \& M. Fearnow-Kenney (Eds.), Improving prevention effectiveness (pp. 83-92). Greensboro, NC: Tanglewood Research Inc. doi:10.1037/0022-3514.67.4.653

Ennett, S., Bauman, K., \& Koch, G. (1994). Variability in cigarette moking within and between adolescent friendship cliques. Addictive Behaviors, 19, 295-305. doi:10.1016/0306-4603(94)90031-0

Epstein, J., Botvin, G., Baker, E., \& Diaz, T. (1999). Impact of social influence and problem behavior on alcohol use among inner city hispanic and black adolescents. Journal of Studies of Alcohol, 60, 595-604.

Farrington, D. (2005). Integrated development and life course theories on offending: Advances in criminological theory. New Brunswick, NJ: Transaction Publishers.

Ferrance, R. (1980). Sex differences in the prevalence of problem drinking. In O. J. Kalant (Ed.), Alcohol and drug problems in women: Research advances in alcohol and drug problems (pp. 69-124). New York: Plenum.

Fillmore, K. (1984). When angels fall: Women's drinking as cultural preoccupation and as reality. In S. C. Wilsnack, \& L. J. Beckman (Eds.), Alcohol problems in women: Antecedents, consequences and interventions (pp. 7-36). New York: Guilford Press.

Fleming, C., Brewer, D., Gainey, R., Haggerty, K., \& Catalano, R. (1997). Parent drug use and bonding to parents as predictors of substance use in children of substance abusers. Journal of Child and Adolescent Substance Abuse, 6, 75-86. doi:10.1300/J029v06n04 04

Foshee, V., \& Bauman, K. (1992). Parental and peer characteristics as modifiers of the bond-behavior relationship: An elaboration of control theory. Journal of Health and Social Behavior, 33, 66-76. doi: $10.2307 / 2136858$

Fraser, J. (1973). The female alcoholic. Addictions, 20, 64-80.

Greenstein, T. N. (1995). Gender ideology, marital disruption and the employment of married women. Journal of Marriage and Family, 57, 31-42. doi: $10.2307 / 353814$

Greenstein, T. N. (1996). Gender ideology and perceptions of the fairness of the division of household labor: Effects on marital quality. Social Forces, 74, 1029-1042.

Gorsuch, R. (1995). Forgiveness: An exploratory factor analysis and its relationships to religious variables. Review of Religious Research, 34, 
333-347. doi: $10.2307 / 3511971$

Hirschi, T. (1969). Causes of delinquency. Berkeley, CA: University of California Press.

Honjo, K., Tsutsumi, A., Kawachi, I., \& Kawakami, N. (2006). What counts for the relationship between social class and smoking cessation? Results of a path analysis. Social Science and Medicine, 62, 317-328. doi:10.1016/j.socscimed.2005.06.011

House, J., Kessler, R., \& Herzog, A. R. (1990). Age, socioeconomic status, and Health. Milbank Quarterly, 68, 383-411. doi:10.2307/3350111

House, J., Lepkowski, J., Kinney, A., Mero, R., Kessler, R., \& Herzog, A. R. (1994). The social stratification of aging and health. Journal of Health and Social Behavior, 35, 213-234. doi:10.2307/2137277

Horwitz, A., \& White, H. (1987). Gender role orientations and styles of pathology among adolescents. Journal of Health and Social Behavior, 28, 158-170. doi: $10.2307 / 2137129$

Johnson, B., Jang, S., Larsen, D., \&. Deli, S. (2001). Does adolescent religious commitment matter? A reexamination of the effects of religiosity on delinquency. Journal of Research on Crime and Delinquency, 38, 22-43. doi:10.1177/0022427801038001002

Kim, M., \& Schneider, R. (2005). Longitudinal trajectories of heavy drinking among adults in the US. Addiction, 161, 91-99.

Kobus, K. (2003). Peers and adolescent smoking. Addictions, 98, 37-55. doi:10.1046/j.1360-0443.98.s1.4.x

Levin, J., \& Taylor, R. (1997). Age differences in patterns and correlates of the frequency of prayer. The Gerontologist, 37, 75-89. doi:10.1093/geront/37.1.75

Lo, C. (2000). Timing of drinking initiation: A trend study among high school seniors. Journal of Drug Issues, 30, 525-554.

Morgan, S., \& Sorensen, A. (1999). Parental networks, social closure and mathematics learning: A test of Coleman's social capital explanation of school effects. American Sociological Review, 64, 661-681. doi: $10.2307 / 2657368$

Neill, C., \& Kahn, A. (1999). The role of personal spirituality and religious social activity on the life satisfaction of older widowed women. Sex Roles, 40, 319-329. doi:10.1023/A:1018811324286

Offer, A., \& Schneider, K. (2007). The challenge of affluence: Selfcontrol and well-being in US. New York: Oxford University Press.

Parker, D., Wolz, M., Parker, E., \& Harford, T. (1980). Sex roles and alcohol consumption: A research note. Journal of Health and Social Behavior, 21, 43-48. doi:10.2307/2136693

Peralta, R., \& Cruz, J. M. (2006). Conferring meaning onto alcoholrelated violence: An analysis of alcohol use and masculinity in a sample of college students. Journal of Men's Studies, 14, 109-125. doi:10.3149/jms.1401.109

Petts, R. (2009). Family, religion and delinquency trajectories. American Sociological Review, 74, 465-483. doi: $10.1177 / 000312240907400307$

Rai, A., Stanton, B., Ying, W., Li, X., Galbraith, J., Cottrell, L., Pack, R., Harris, C., D’Alessandri, D., \& Burns, J. (2003). Relative influences of perceived parental monitoring perceived peer involvement on adolescent risk behaviors: An analysis of six cross-sectional data sets. Journal of Adolescent Health, 33, 108-118. doi:10.1016/S1054-139X(03)00179-4

Rhule-Louie, D., \& McMahon, R. (2007). Problem behavior and romantic relationships: Assortative mating, behavior contagion, and desistance. Clinical Child and Family Psychology Review, 10, 53-100. doi:10.1007/s10567-006-0016-y
Robbins, C. (1989). Sex differences in psychosocial consequences of alcohol and drug abuse. Journal of Health and Social Behavior, 30, 117-130. doi: $10.2307 / 2136917$

Rohrbaugh, J., \& Jessor, R. (1975). Religiosity in youth: A personal control against deviant behavior. Journal of Personality, 43, 136-155. doi:10.1111/j.1467-6494.1975.tb00577.x

Sampson, R., \& Laub, J. (1993). Crime in the MAKING: Pathways and turning points through life. Cambridge, MA: Harvard University Press.

Sampson, R., \& Laub, J. (2005). A life-course view of the development of crime. The Annals of the American Academy of Political and Social Science, 602, 12-45. doi:10.1177/0002716205280075

Sampson, R., Laub, J., \& Wimer, C. (2006). Does marriage reduce crime? A counterfactual approach to within-individual causal effects. Criminology, 44, 65-508. doi:10.1111/j.1745-9125.2006.00055.x

Sieving, R., Perry, C., \& Williams, C. (2000). Do friendships change behaviors or do behaviors change friendships: Examining paths of influence in young adolescents' alcohol use. Journal of Adolescent Health, 26, 27-35. doi:10.1016/S1054-139X(99)00056-7

Smith, C. (2003). Theorizing religious effects among American adolescents. Journal for the Scientific Study of Religion, 42, 17-30. doi:10.1111/1468-5906.t01-1-00158

Sullivan, P. (1991). The genetic epidemiology of smoking. Nicotine and Tobacco Research, 1, S51-S59.

Sussman, S., Dent, C., Stacey, A., Burciaga, C., Raynor, A., Turner, G., Charlin, V., Craig, S., Hansen, W., Burton, D., \& Flay, B. (1990). Peergroup association and adolescent tobacco use. Journal of Abnormal Psychology, 99, 349-352.

Temple, M. (1987). Alcohol use among male and female college students: Has there been a convergence? Youth and Society, 19, 44-72.

Unger, J., Rohrbach, L., Cruz, T., Baezconde-Garbanati, L., Howard, K., Palmer, P., \& Johnson, C. (2001). Ethnic variation in peer influences on adolescent smoking. Nicotine and Tobacco Research, 3, 167-176. doi:10.1080/14622200110043086

Valente, T. (2003). Social network influences on adolescent substance use: An introduction. Connections, 25, 11-16.

Wallace, J. J., \& Bachman, J. (1991). Explaining racial/ethnic differences in adolescent substance use: The impact of background and lifestyle. Social Problems, 38, 333-355. doi:10.2307/800603

Wechsler, H. (1980). Epidemiology of male/female drinking over the last half century. In V. Pinhas (Ed.), Alcoholosm and alcohol abuse among women: Research issues (pp. 54-82). Washington DC: US Government Printing Office.

Wentworth, D. K., \& Chell, R. M. (2005). Gender identity at home: Comparing the role of househusband to housewife. In J. W. Lee (Ed.), Psychology of gender identity (pp. 113-126). Hauppauge, NY: Nova Biomedical.

Wilsnack, R., \& Wilsnack, S. (1978). Sex roles and drinking among adolescent girls. Journal of Studies on Alcohol, 39, 1855-1874.

Wilsnack, R., \& Wilsnack, S. (1980). Drinking and denial of social obligations among adolescent boys. Journal of Studies on Alcohol, 41, 1118-1133. doi:10.2105/AJPH.74.11.1231

Wilsnack, R., Wilsnack, S., \& Klassen, A. (1984). Women's drinking and drinking problems: Patterns from a 1981 national survey. American Journal of Public Health, 74, 1231-1238.

Windle, M. (2000). Parental, sibling and peer influences on adolescent substance use and alcohol problems. Applied Developmental Sciences, 4, 98-110. doi:10.1207/S1532480XADS0402_5 